\title{
An Economic Production Quantity Model for Atlantic Pharmaceuticals Laboratories
}

\author{
Usman Ghani ${ }^{1}$, Mubashir Hayat ${ }^{2}$, Imran Ghani $^{3}$ \\ ${ }^{1,2}$ Department of Mechanical Engineering, \\ University of Engineering and Technology Peshawar, Jalozai Campus \\ ${ }^{3}$ United Bank Limited \\ ${ }^{1}$ usmanghani@uetpeshawar.edu.pk
}

\begin{abstract}
Inventory in an industry is considered like a blood in the body, and almost $50 \%$ of investment is made on inventory. Therefore, keeping the optimum level of inventory at low possible cost is the primary focus of researchers. Industries have to make good choices for inventory management in order to compete in market and meet the demands. Major issues regarding inventory in pharmaceutical industry are overstock, unjustified forecasting technique, long manufacturing lead times and lack of IT support. For these reasons, optimizing inventory is more difficult for pharmaceutical companies as compared to other manufacturing companies. Such issues are also faced by Atlantic Pharmaceuticals Laboratories (APL). In order to address these issue, inventory management is performed in APL. Inventory is categorized in three classes through $\mathrm{ABC}$ analysis. Class $\mathrm{A}$ items are further analyzed and their optimum quantity is determined by EPQ model. At the end sensitivity analyses are performed to determine the most and least critical parameters of the model.
\end{abstract}

Keywords: Inventory management, ABC Analysis, EPQ model, Sensitivity analysis

\section{INTRODUCTION}

Determining the right level of inventory in any organization has been the primary focus nowadays. In order to survive and groom up in modern competition, the organization has to make good decision about its inventory. Here the focus is on an inventory management in Atlantic Pharmaceutical laboratories (APL). Inventory may consist of foods, finished products and raw materials that contain financial value and are stored by any company or firm in different forms in its supervision waiting for various operations such as stuffing or sale of products in the future point of view. Inventory management system tracks products with entire supply chain or the portion of it. Thus, inventory management system covers everything from the production to retailers, warehousing to packing so that all the movements of stock \& parts between the manufacturer and retailer is done in optimum way. We mean that one of the business company can see all the movements of the small parts of its processes, which can help to make healthy decisions and investments, different managers focus on different parts of the supply chain. That's why small business focuses or concentrates at the end of the sales of the chain.

Whenever there is a good tracking stuff then there are a lot of chances to make investment and take advantages of that. When we track our product then we estimate that how to much we can sell in the future, we can find out it for the customer and reorder whenever there is stock out appearance. For this purpose, that when to do tracking, predicting and reordering is to use an inventory management system. We will look at what that means, what are the parameters to be lookout for, and what how we can accomplish a good inventory system in place. Inventory is a very important stuff that the company need to keep for different activities. To keep the inventory optimum this is the desired objective of each and every company. Overstock and shortage of inventory both damage economical influence and health of the commercial as well as disturb business events. Technology is used in probably each and every field of inventory management to help control, monitor, and analyze inventory level. Computers, especially, play a massive role in current inventory management.

Inventory is the expensive assists of any organizations which covers $50 \%$ of the total capital investment just on inventory. Operation controller of the entire world have considered that inventory management is very important because a company can reduced inventory cost by reducing their inventory also the stock out can result in customers dissatisfaction. All of the organization have their own inventory about which they are carrying to control it through some methods and planning i.e. a bank has its inventory management system for cash to control it. Like other organization, Hospitals control the inventory of types of blood, pharmaceutical's, Library controls inventory of books, Government agencies, schools, colleges, restaurant's and that's why almost every production firm is looking to control their inventory through some methods and planning. 


\section{A. Problem Description}

APL deals with products like syrup, suspension and infusion, the raw material which is ordered for such kind of product is through experienced guess not through technical method, which often cause the shortage of inventory or excess of inventory, and causing additional cost. Thus, developing a technique for this kind of problem and making sure that, the desired demand is fulfilled exactly when the customer needs it with minimum inventory cost associated.

\section{B. Objectives}

The main objective of the inventory management is to make an equilibrium between inventory investment and customer service. Applying the best methodology based on the inventory problem to achieve the following objectives:

- Optimum inventory level

- Minimum inventory cost

\section{LITERATURE REVIEW}

Everyone knows that inventory management plays the major role in every type of business organization to flourish it. Production Order Quantity (POQ) model is one of the most common inventory model which is used in inventory control techniques. This almost the first inventory model developed by Harris in 1913. This model calculates the quantity in order to minimize inventory cost, by determining the optimum level for the related costs. This model tells us about the level of optimum amount of items production and therefore it is mostly applicable to manufacturing organization. S.M. Samak- Kulkarni contributed in the determination of finest inventory model for decreasing inventory cost [1]. Inventory is the stuff of raw material, WIP and finished goods used in organization. To solve order related problems, they present some models on which they work to solve inventory related problem which will reduce the total inventory cost and will optimize the inventory level. These papers take into consideration lot by lot size, economic order quantity (EOQ), periodic order quantity (POQ) and Wagner Within algorithm. In this paper total inventory cost for many items are determined for each method so in the results after calculation for each model the Wagner Within algorithm gives the optimum cost in each case.

Lt Col Gupta researched to control the inventory of medical store by using ABC-VED analysis in a combination to divide the whole inventory in three categories I, II, and III [2]. The methods which were used by the authors in this case study are ABC-VED analysis, and the economic analysis of the Pharmaceutical Spending of Priced Vocabulary Stores (PVMS) section 01 hospital for the year 2003 was under consideration which was consists of 190 bedded service. The total drugs were 493 drugs in PVMS Section 01, and in these drugs only 325 were being used in the reference hospital which costs about 55,23,503 rupees. So this 325 drugs were categorize in such a way that 47 drugs (about $14.4 \%$ ) were added to category A which consume $70 \%$ of the total expenditure because these drugs were high in the cost but were low in the amount (about 14.4\%) as mentioned earlier, Hooshang researched on inventory management by using $\mathrm{ABC}$ Classification and decision support system with a clinical laboratory application [3]. For this clinical laboratory the $\mathrm{ABC}$ classification is based on the criteria of annual dollar volume which categorize the items intro three classes. The Pareto principle is usually applicable to $\mathrm{ABC}$ classification which suppose that $20 \%$ of the items will generate $80 \%$ of the annual dollar volume of the demand. So, this idea motivate inventory controller to concentrate on few of the items of the inventory which are the most critical items regarding annual dollar value.

The class A items are the highest annual dollar demand items (about 78-80\%) of the budget which are forcefully managed which requires a high attention from both class B and C items. The $15-20 \%$ of the total items of the laboratory include in class A which is less but very critical due to its annual dollar value while $15-25 \%$ annual dollar volume generates by class $\mathrm{B}$ which included $25-30 \%$ of the items and class $\mathrm{C}$ with low annual dollar volume values but includes large portion of the inventory. The Class B and Class $\mathrm{C}$ items are placed at a higher level than Class A items. The company uses ABC classification for the 47 items in which the first 8 items were classified in Class A which accounted for $77 \%$ of the annual demand cost. 4 items were classified in Class B and the remaining 17 items were classified in Class $\mathrm{C}$ using Lean Production, Organizational Performance and Inventory Management [4]. The purpose of this case study was to check the hypothesis that with the implementation of lean inventory management will leads to improve the financial performance of a firm. Now in this case study they analyze the data which came from the ICAP database, which includes financial information. The data were taken in between 2000 and 2002 period which was the sample period for the data analysis. The industrials sectors which were selected in Greece were Food, Textiles and Chemicals. Initial results, from this analysis obtained that the higher the level of inventories conserved by a firm, the lower will be its rate of return.

This kind of inventory models has attracted the attention of several researchers such as Sarkar, Chaudhuri, \& Sana [5], Sarkar, Sana, \& Chaudhuri [5,6,7], Sarker, Jamal, \& Mondal [8], Sana \& Chaudhuri[6], Chug [9], Sarkar $[10,11,12]$, Widyadana and Wee [13], Chang, Su, Yang, \& Weng, [14]) and Cárdenas-Barrón, Sarkar, \& TreviñoGarza [15], Cárdenas-Barrón, Taleizadeh, \& Treviño-Garza [16] , just to name a few works. MS Mahatme, et al 
[17] researched an integrated Economic model analysis of a Teriary Care Hospital in Central India. Financial study plays an essential role in the management of medical store. Hospital inventory management system should ensure the optimum stock of all the required items to keep the supply without any interruption. About one third of the hospital revenue is spent on the materials and pharmaceuticals. So, this gives importance to manage and control the important drugs in the medical store. The main purpose of this case study was to control the inventory of the medical store by controlling VED analysis with EOQ after the comparison of indexed cost and the actual cost.

\section{METHODOLOGY}

As mentioned before the industry, which is selected for the proposed work is Atlantic Pharmaceuticals Laboratories (APL). The production process of any pharmaceuticals industry for syrup and suspension production is given in figure 1. APL deal with different products like syrups, suspension and infusion and they follows the same process.

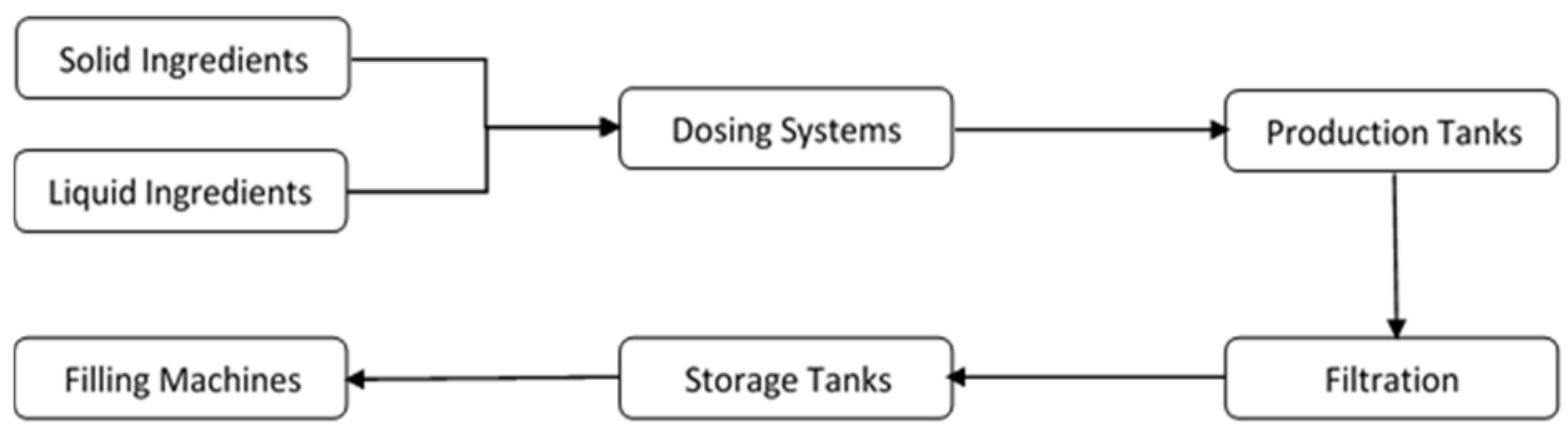

Fig. 1 Production process of Atlantic Pharmaceuticals Laboratories.

First of all, solid ingredients are dissolved into liquid (mostly purified water) and then through dosing systems are fed into the production tanks according to the formulation. The dosing system is powered by an electric motor and has a controller that turns the pump on and off and managed the flow rate. In production tanks the solution is taken to the required temperate and necessary production processes are performed. After the production, the solid particles are separated from the solution through the process of filtration. All the products dispense extemporaneously are stored in the storage tanks and then filled in the bottles when required.

\section{A. Data Collection}

APL produces three kinds of products i.e. Syrups, Suspension and Infusions. Table I given below tells about the type of product its registration number their package size and cost associated per unit. For example, look at the product no 1, it shows that it is syrup by name of Acitral having registration no 62316 with a generic name of Sodium acid citrate. The packing of Acitral is $120 \mathrm{ml}$ per pack or bottle with a unit cost of Rs.19. 
Table I. Detail of the products in Atlantic Pharmaceuticals Laboratories.

\begin{tabular}{|c|c|c|c|c|c|}
\hline S.NO & $\begin{array}{c}\text { Syrup/Suspention } \\
\text { /Infusion }\end{array}$ & Reg. NO & Generic Name & Pack ml & $\begin{array}{c}\text { Unit } \\
\text { Cost } \\
\text { (PKR) }\end{array}$ \\
\hline 1 & Syp. Acitral & 62316 & Sod.acide citrate & 120 & 19 \\
\hline 2 & Susp.Alusim & 62321 & Al.Hydroxide+Mg.Hydroxide & 120 & 19 \\
\hline 3 & Susp.Alusim & 62321 & Al.Hydroxide+Mg.Hydroxide & 240 & 35 \\
\hline 4 & Susp.Calco-D & 68497 & Calcium Phosphate+Vit-D & 120 & 19 \\
\hline 5 & Susp.Calco-D & 68497 & Calcium Phosphate+Vit-D & 240 & 35 \\
\hline 6 & Syp. Cetrazit & 68499 & Cetrizine Dihydrocloride & 60 & 15 \\
\hline 7 & Susp.Dilox-M & 62323 & Diloxanide Furoate+Met.Benzoate & 60 & 24 \\
\hline 8 & Susp.Epodom & 62318 & Domperidone & 120 & 23 \\
\hline 9 & Susp.Fempol & 62314 & Paracetamol 120mg & 60 & 15 \\
\hline 10 & Susp.Fempol 6+ & 62315 & Paracetamol 250mg & 60 & 17 \\
\hline 11 & Susp.Fempol C & 73363 & Paracetamol + Chlophenramine & 60 & 16.5 \\
\hline 12 & Syp. Hydilar & 62325 & Aminophylline,Diphenhydramine & 120 & 18 \\
\hline 13 & Syp.Hydilar DM & 62317 & Diphenhydramine,Dextromethorphen & 120 & 23 \\
\hline 14 & Syp.Metopride & 62322 & Metochlopramide HCL & 50 & 16 \\
\hline 15 & Susp.Metrosol & 73362 & Metronidazole as Benzoate & 60 & 19 \\
\hline 16 & Susp.Pepticral & 73365 & Sucralfate & 60 & 46 \\
\hline 17 & Susp.Pironec & 62324 & Ibuprofen & 90 & 20 \\
\hline 18 & Syp.Rediron & 73364 & Iron Polymaltose & 120 & 25 \\
\hline 19 & Syp.Rediron & 73364 & Iron Polymaltose & 240 & 47 \\
\hline 20 & Syp.Pizo & 68500 & Pizotifen & 60 & 20 \\
\hline 21 & Syp.Pizo & 68500 & Pizotifen & 120 & 25 \\
\hline 22 & Syp.Ventasol & 73366 & Sulbotamol & 60 & 14.5 \\
\hline 23 & Syp.Zinsol & 96701 & Zinc Sulphate & 60 & 17 \\
\hline 24 & Susp.Zoprim & 62319 & Trimethoprim,Sulfamethoxazole $200 \mathrm{mg}$ & 50 & 18 \\
\hline 25 & Susp.Zoprim DS & 62320 & Trimethoprim,Sulfamethoxazole $400 \mathrm{mg}$ & 50 & 23 \\
\hline 26 & Metrosol Inf & 11768 & Metronidazole 500mg & 100 & 24 \\
\hline 27 & Ciprosol Inf & 47720 & Ciprofloxacine $200 \mathrm{mg}$ as Lactate & 100 & 29 \\
\hline 28 & Lefosol Inf & 46104 & Levofloxacine $500 \mathrm{mg}$ & 100 & 31 \\
\hline 29 & Oflocin-sol Inf & 46105 & Ofloxacine 200mg & 100 & 28 \\
\hline 30 & Transol 5\% & 52478 & Dextrose $5 \%$ & 100 & 19 \\
\hline 31 & Transol DS & 52479 & Dextrose $5 \%+\mathrm{Nacl} 0.9 \%$ & 100 & 20 \\
\hline 32 & Transol N/S & 52480 & Sodium Chloride $0.9 \%$ & 100 & 18 \\
\hline
\end{tabular}

In data collection the first thing is to know how many different kinds of products in the industry producing. APL is producing 32 types of products which include syrups (syp), Suspensions (Susp) and infusions (Inf). The monthly demand of each item from January to December is shown in the table below. The Demand given here is in cottons. Look at the item no 1 with registration no 62316, it shows that the demand of this particular item in January is 300 cottons, in February 308 cottons and so on as shown in Table II. 
Table II. Monthly demand for each item.

\begin{tabular}{|c|c|c|c|c|c|c|c|c|c|c|c|c|c|c|c|c|}
\hline S.NO & Reg. NO & Jan & Feb & Mar & Apr & May & Jun & Jul & Aug & Sep & $0 \mathrm{ct}$ & Nov & Dec & $\begin{array}{c}\text { Avg. } \\
\text { Monthly } \\
\text { Demand } \\
\text { (Cotton) }\end{array}$ & $\begin{array}{c}\text { Bottles } \\
\text { per } \\
\text { Cotton }\end{array}$ & $\begin{array}{l}\text { Avg.Total } \\
\text { Monthly } \\
\text { Demand } \\
\text { (Bottles) }\end{array}$ \\
\hline 1 & 62316 & 300 & 308 & 298 & 312 & 290 & 295 & 300 & 310 & 290 & 290 & 310 & 305 & 301 & 70 & 21070 \\
\hline 2 & 62321 & 300 & 290 & 304 & 295 & 304 & 308 & 308 & 304 & 298 & 307 & 302 & 292 & 301 & 70 & 21070 \\
\hline 3 & 62321 & 100 & 98 & 108 & 106 & 95 & 95 & 106 & 105 & 90 & 90 & 100 & 105 & 100 & 50 & 5000 \\
\hline 4 & 68497 & 200 & 200 & 190 & 195 & 215 & 205 & 195 & 190 & 190 & 210 & 205 & 205 & 200 & 70 & 14000 \\
\hline 5 & 68497 & 80 & 65 & 90 & 85 & 88 & 70 & 78 & 78 & 80 & 86 & 78 & 82 & 80 & 50 & 4000 \\
\hline 6 & 68499 & 500 & 480 & 485 & 510 & 495 & 505 & 498 & 498 & 506 & 518 & 512 & 492 & 500 & 100 & 50000 \\
\hline 7 & 62323 & 200 & 198 & 210 & 208 & 190 & 190 & 215 & 215 & 186 & 190 & 190 & 205 & 200 & 100 & 20000 \\
\hline 8 & 62318 & 100 & 100 & 108 & 90 & 95 & 105 & 95 & 104 & 108 & 112 & 104 & 90 & 101 & 70 & 7070 \\
\hline 9 & 62314 & 1000 & 1030 & 990 & 990 & 1014 & 1020 & 980 & 995 & 1018 & 1025 & 995 & 1000 & 1005 & 100 & 100500 \\
\hline 10 & 62315 & 800 & 810 & 812 & 791 & 792 & 807 & 812 & 800 & 796 & 794 & 796 & 810 & 802 & 100 & 80200 \\
\hline 11 & 73363 & 500 & 488 & 495 & 508 & 505 & 505 & 495 & 496 & 520 & 516 & 494 & 502 & 502 & 100 & 50200 \\
\hline 12 & 62325 & 125 & 120 & 130 & 128 & 112 & 120 & 133 & 132 & 125 & 128 & 127 & 130 & 126 & 70 & 8820 \\
\hline 13 & 62317 & 75 & 77 & 72 & 79 & 65 & 70 & 78 & 75 & 72 & 78 & 78 & 76 & 75 & 70 & 5250 \\
\hline 14 & 62322 & 100 & 94 & 103 & 110 & 98 & 92 & 115 & 90 & 95 & 98 & 108 & 108 & 101 & 120 & 12120 \\
\hline 15 & 73362 & 500 & 500 & 490 & 502 & 505 & 515 & 498 & 490 & 508 & 517 & 502 & 496 & 502 & 100 & 50200 \\
\hline 16 & 73365 & 50 & 48 & 55 & 55 & 45 & 49 & 52 & 56 & 49 & 54 & 54 & 57 & 52 & 100 & 5200 \\
\hline 17 & 62324 & 1000 & 1014 & 1005 & 994 & 986 & 995 & 1015 & 1008 & 996 & 990 & 1018 & 1003 & 1002 & 80 & 80160 \\
\hline 18 & 73364 & 300 & 300 & 306 & 295 & 315 & 315 & 310 & 294 & 286 & 290 & 308 & 305 & 302 & 70 & 21140 \\
\hline 19 & 73364 & 100 & 108 & 106 & 97 & 98 & 108 & 110 & 107 & 100 & 92 & 95 & 102 & 102 & 50 & 5100 \\
\hline 20 & 68500 & 200 & 208 & 205 & 194 & 190 & 186 & 204 & 208 & 202 & 212 & 209 & 205 & 202 & 100 & 20200 \\
\hline 21 & 68500 & 400 & 394 & 410 & 414 & 398 & 394 & 392 & 402 & 417 & 397 & 404 & 396 & 402 & 70 & 28140 \\
\hline 22 & 73366 & 100 & 108 & 115 & 94 & 102 & 92 & 97 & 95 & 114 & 98 & 95 & 113 & 102 & 100 & 10200 \\
\hline 23 & 96701 & 200 & 196 & 195 & 207 & 198 & 205 & 200 & 214 & 187 & 208 & 205 & 196 & 201 & 100 & 20100 \\
\hline 24 & 62319 & 100 & 95 & 110 & 98 & 95 & 90 & 112 & 108 & 104 & 95 & 95 & 106 & 101 & 120 & 12120 \\
\hline 25 & 62320 & 100 & 100 & 102 & 115 & 98 & 92 & 94 & 97 & 112 & 110 & 96 & 106 & 102 & 120 & 12240 \\
\hline 26 & 11768 & 250 & 244 & 248 & 245 & 252 & 260 & 254 & 240 & 256 & 262 & 253 & 260 & 252 & 70 & 17640 \\
\hline 27 & 47720 & 500 & 518 & 510 & 493 & 489 & 497 & 510 & 494 & 515 & 520 & 506 & 508 & 505 & 70 & 35350 \\
\hline 28 & 46104 & 50 & 55 & 54 & 49 & 48 & 53 & 50 & 44 & 49 & 47 & 57 & 55 & 51 & 70 & 3570 \\
\hline 29 & 46105 & 50 & 58 & 47 & 51 & 48 & 46 & 53 & 58 & 55 & 60 & 58 & 52 & 53 & 70 & 3710 \\
\hline 30 & 52478 & 1000 & 986 & 990 & 1012 & 996 & 1020 & 1022 & 1005 & 995 & 998 & 1018 & 1005 & 1004 & 70 & 70280 \\
\hline 31 & 52479 & 100 & 104 & 98 & 92 & 116 & 105 & 97 & 88 & 104 & 111 & 98 & 108 & 102 & 70 & 7140 \\
\hline 32 & 52480 & 800 & 794 & 798 & 812 & 815 & 808 & 793 & 785 & 810 & 810 & 818 & 815 & 805 & 70 & 56350 \\
\hline
\end{tabular}

At the end of the year the average monthly demand is 301 cottons and as 1 cotton contains 70 units, therefore is 21070 units demand in average for this particular item.

\section{B. Data Analysis}

Data is analyzed so that it becomes easier to understand the data and become more help full in problem solving. Here $\mathrm{ABC}$ analysis technique is followed, which divides the on-hand inventory into three classes $\mathrm{A}, \mathrm{B}$ and $\mathrm{C}$ on the basis of annual dollar volume as shown in Table III. The detail of each class is discussed in an earlier chapter. 
Table. III Item categorization through ABC analysis.

\begin{tabular}{|c|c|c|c|c|c|c|c|}
\hline Rank & Reg. NO & $\begin{array}{c}\text { Unit } \\
\text { Cost } \\
\text { (PKR) }\end{array}$ & $\begin{array}{l}\text { Avg. Total } \\
\text { Monthly } \\
\text { Demand } \\
\text { (Bottles) } \\
\end{array}$ & $\begin{array}{l}\text { Monthly } \\
\text { Cost } \\
\text { (PKR) }\end{array}$ & $\begin{array}{l}\text { Percent of } \\
\text { Monthly } \\
\text { Cost }\end{array}$ & $\begin{array}{c}\text { Cumulative } \\
\text { Percent }\end{array}$ & Category \\
\hline 1 & 62324 & 20 & 80160 & 1603200 & 9.56 & 9.56 & $\mathrm{~A}$ \\
\hline 2 & 62314 & 15 & 100500 & 1507500 & 8.99 & 18.56 & A \\
\hline 3 & 62315 & 17 & 80200 & 1363400 & 8.13 & 26.69 & $\mathrm{~A}$ \\
\hline 4 & 52478 & 19 & 70280 & 1335320 & 7.97 & 34.66 & A \\
\hline 5 & 47720 & 29 & 35350 & 1025150 & 6.12 & 40.77 & A \\
\hline 6 & 52480 & 18 & 56350 & 1014300 & 6.05 & 46.82 & A \\
\hline 7 & 73362 & 19 & 50200 & 953800 & 5.69 & 52.51 & B \\
\hline 8 & 73363 & 16.5 & 50200 & 828300 & 4.94 & 57.45 & B \\
\hline 9 & 68499 & 15 & 50000 & 750000 & 4.47 & 61.93 & $\mathrm{~B}$ \\
\hline 10 & 68500 & 25 & 28140 & 703500 & 4.20 & 66.12 & B \\
\hline 11 & 73364 & 25 & 21140 & 528500 & 3.15 & 69.28 & B \\
\hline 12 & 62323 & 24 & 20000 & 480000 & 2.86 & 72.14 & B \\
\hline 13 & 11768 & 24 & 17640 & 423360 & 2.53 & 74.66 & $\mathrm{~B}$ \\
\hline 14 & 68500 & 20 & 20200 & 404000 & 2.41 & 77.07 & $\mathrm{~B}$ \\
\hline 15 & 62316 & 19 & 21070 & 400330 & 2.39 & 79.46 & B \\
\hline 16 & 62321 & 19 & 21070 & 400330 & 2.39 & 81.85 & $\mathrm{C}$ \\
\hline 17 & 96701 & 17 & 20100 & 341700 & 2.04 & 83.89 & $\mathrm{C}$ \\
\hline 18 & 62320 & 23 & 12240 & 281520 & 1.68 & 85.57 & $\mathrm{C}$ \\
\hline 19 & 68497 & 19 & 14000 & 266000 & 1.59 & 87.15 & $\mathrm{C}$ \\
\hline 20 & 73364 & 47 & 5100 & 239700 & 1.43 & 88.58 & $\mathrm{C}$ \\
\hline 21 & 73365 & 46 & 5200 & 239200 & 1.43 & 90.01 & $\mathrm{C}$ \\
\hline 22 & 62319 & 18 & 12120 & 218160 & 1.30 & 91.31 & $\mathrm{C}$ \\
\hline 23 & 62322 & 16 & 12120 & 193920 & 1.16 & 92.47 & C \\
\hline 24 & 62321 & 35 & 5000 & 175000 & 1.04 & 93.51 & $\mathrm{C}$ \\
\hline 25 & 62318 & 23 & 7070 & 162610 & 0.97 & 94.48 & $\mathrm{C}$ \\
\hline 26 & 62325 & 18 & 8820 & 158760 & 0.95 & 95.43 & $\mathrm{C}$ \\
\hline 27 & 73366 & 14.5 & 10200 & 147900 & 0.88 & 96.31 & $\mathrm{C}$ \\
\hline 28 & 52479 & 20 & 7140 & 142800 & 0.85 & 97.16 & $\mathrm{C}$ \\
\hline 29 & 68497 & 35 & 4000 & 140000 & 0.84 & 98.00 & $\mathrm{C}$ \\
\hline 30 & 62317 & 23 & 5250 & 120750 & 0.72 & 98.72 & $\mathrm{C}$ \\
\hline 31 & 46104 & 31 & 3570 & 110670 & 0.66 & 99.38 & $\mathrm{C}$ \\
\hline 32 & 46105 & 28 & 3710 & 103880 & 0.62 & 100.00 & $\mathrm{C}$ \\
\hline
\end{tabular}

The table above shows us the ABC classification. The rank shows that which one item contributes more to the monthly cost. Take for example rank 1 item with the unit cost of 20 PKR have a demand of 80160 units with monthly cost of 1603200 PKR contributing the highest cost to the monthly inventory cost with 9.56 percent. Similarly, you can see for the other item. The number of items in class A are six contributing to all most $50 \%$ of total inventory cost. Similarly, Class B items are nine and class C are 17 contributing $30 \%$ and $20 \%$ to the total inventory cost respectively. The first two classes A and B are further taken for the management as they are involved in the $80 \%$ cost of inventory.

POQ model is used when inventory sizes up over a period of time after an order is placed. It is also used when units are produced and are sold at the same time. The equation for Optimum production quantity is given below:

$$
Q_{P}^{*}=\sqrt{\frac{2 D S}{H\left[1\left(-\frac{d}{P}\right)\right]}}
$$


Where,

$\mathrm{Q}_{\mathrm{p}}^{*}=$ Optimum number of units per order

$\mathrm{H}=$ Holding cost per unit per year

$\mathrm{p}=$ Daily production rate

$\mathrm{d}=$ Daily demand rate, or usage rate

$\mathrm{t}=$ Length of the production run in days

$\mathrm{H}=$ (unit cost) (interest rate i)

Working days per year $=250$

Interest Rate $\mathrm{i}=10 \%$

Total Cost TC $=\frac{\mathrm{D}}{\mathrm{Q}} \mathrm{S}+\frac{\mathrm{Q}}{2} \mathrm{H}$

The calculated $\mathrm{Q}_{\mathrm{p}}^{*}$ and TC for the 15 items which includes six items of class A and nine of class B are given in the table below.

Table IV. Optimum production and total cost for class A and B items.

\begin{tabular}{|c|c|c|c|c|c|c|c|}
\hline Rank & Reg. NO & $\begin{array}{c}\text { Daily } \\
\text { Demand }\end{array}$ & $\begin{array}{c}\text { Daily } \\
\text { Production }\end{array}$ & $\begin{array}{c}\text { Holding Cost } \\
\text { (PKR) }\end{array}$ & $\begin{array}{c}\text { Setup Cost } \\
\text { (PKR) }\end{array}$ & $\begin{array}{c}\mathbf{Q}^{*} \boldsymbol{p} \\
\text { (Units) }\end{array}$ & $\begin{array}{c}\text { TC } \\
\text { (PKR) }\end{array}$ \\
\hline 1 & 62324 & 3847.68 & 3855 & 2 & 40 & 142349.6 & 80640 \\
\hline 2 & 62314 & 4824 & 4834 & 1.5 & 24 & 136584.7 & 75663 \\
\hline 3 & 62315 & 3849.6 & 3860 & 1.7 & 30 & 112280.9 & 68530 \\
\hline 4 & 52478 & 3373.44 & 3400 & 1.9 & 35 & 63067.3 & 67186 \\
\hline 5 & 47720 & 1696.8 & 1730 & 2.9 & 48 & 27050.5 & 51833.5 \\
\hline 6 & 52480 & 2704.8 & 2738 & 1.8 & 27 & 40902.1 & 51039 \\
\hline 7 & 73362 & 2409.6 & 2428 & 1.9 & 26 & 46642.6 & 48002 \\
\hline 8 & 73363 & 2409.6 & 2435 & 1.65 & 37 & 50891.9 & 41859 \\
\hline 9 & 68499 & 2400 & 2391 & 1.5 & 54 & 107129.8 & 38148 \\
\hline 10 & 68500 & 1350.72 & 1342 & 2.5 & 60 & 49944.9 & 35895 \\
\hline 11 & 73364 & 1014.72 & 1050 & 2.5 & 48 & 17027.0 & 27001 \\
\hline 12 & 62323 & 960 & 948 & 2.4 & 63 & 31550.0 & 24756 \\
\hline 13 & 11768 & 846.72 & 894 & 2.4 & 41 & 11694.2 & 21660 \\
\hline 14 & 68500 & 969.6 & 1032 & 2 & 45 & 13431.4 & 20740 \\
\hline 15 & 62316 & 1011.36 & 1083 & 1.9 & 34 & 11696.0 & 20424.5 \\
\hline
\end{tabular}

Now the total cost here is calculated on the basis of optimum production quantity $Q_{p}^{*}$. After that the sensitivity analysis comes which helps in finding the most critical variable or variables which can affect the TC with large scale when they are manipulated.

\section{NUMERICAL COMPUTATION AND SENSITIVITY ANALYSIS}

This includes the sensitivity analyses for all the items of class A which were selected as a critical product and are more responsible for inventory cost. The analysis performed for each is given below in detail.

A. Computation for Item No. 1

The data for Susp. Pironec the key variables are taken with appropriate units as follows: $\mathrm{D}=961920$ units/year, $\mathrm{Q}=80160$ units/order, $\mathrm{H}=2 \mathrm{Rs} / \mathrm{unit}, \mathrm{S}=40 /$ lot size, daily demand $\mathrm{d}=3847.68$ units, and daily production rate $\mathrm{p}$ $=3855$ units

$$
\begin{gathered}
Q_{P}^{*}=\sqrt{\frac{2 D S}{H\left[1\left(-\frac{d}{P}\right)\right]}} \\
Q_{P}^{*}=\sqrt{\frac{2 * 961920 * 40}{2\left[1\left(-\frac{3847.68}{3855}\right)\right]}} \\
Q_{P}^{*}=142349.6 \text { Units }
\end{gathered}
$$


Total Cost $T C=\frac{D}{Q} S+\frac{Q}{2} H$

$$
\begin{gathered}
T C=\frac{961920}{80160} 40+\frac{80160}{2} 2 \\
T C=R s .80640
\end{gathered}
$$

\begin{tabular}{|c|c|c|c|c|}
\hline Parameter & Changes & Changes (in \%) & Total Cost & Total Cost (in \%) \\
\hline \multirow[t]{4}{*}{$\mathrm{D}$} & 1442880 & +50 & 80880 & 0.2976 \\
\hline & 1202400 & +25 & 80760 & 0.1488 \\
\hline & 721440 & -25 & 80520 & -0.1488 \\
\hline & 480960 & -50 & 80400 & -0.2976 \\
\hline \multirow[t]{4}{*}{ Q } & 120240 & +50 & 120560 & 49.5040 \\
\hline & 100200 & +25 & 100584 & 24.7321 \\
\hline & 60120 & -25 & 60760 & -24.6528 \\
\hline & 40080 & -50 & 41040 & -49.1071 \\
\hline \multirow[t]{4}{*}{$\mathrm{H}$} & 3 & +50 & 120720 & 49.7024 \\
\hline & 2.5 & +25 & 100680 & 24.8512 \\
\hline & 1.5 & -25 & 60600 & -24.8512 \\
\hline & 1 & -50 & 40560 & -49.7024 \\
\hline \multirow[t]{4}{*}{$\mathrm{S}$} & 60 & +50 & 80880 & 0.2976 \\
\hline & 50 & +25 & 80760 & 0.1488 \\
\hline & 30 & -25 & 80520 & -0.1488 \\
\hline & 20 & -50 & 80400 & -0.2976 \\
\hline
\end{tabular}

Table V. Sensitivity analysis for the key parameters of item no. 1

B. Computation for Item No. 2

The data for Susp.Fempol the key variables are taken with appropriate units as follows: $\mathrm{D}=1206000$ units/year, $\mathrm{Q}=100500$ units/order, $\mathrm{H}=1.5 \mathrm{Rs} /$ unit, $\mathrm{S}=24 \mathrm{Rs} /$ lot size, daily demand $\mathrm{d}=4824$ units, and daily production rate $\mathrm{p}=4834$ units

$$
\begin{gathered}
Q_{P}^{*}=\sqrt{\frac{2 D S}{H\left[1\left(-\frac{d}{P}\right)\right]}} \\
Q_{P}^{*}=\sqrt{\frac{2 * 1206000 * 24}{1.5\left[1\left(-\frac{4824}{4834}\right)\right]}} \\
Q_{P}^{*}=136584.7 \text { Units } \\
T C=\frac{1206000}{100500} 24+\frac{100500}{2} 1.5 \\
T C=R s .75663
\end{gathered}
$$


Table VI. Sensitivity analysis for the key parameters of item no. 2

\begin{tabular}{|c|c|c|c|c|}
\hline Parameter & Changes & Changes (in \%) & Total Cost & Total Cost (in \%) \\
\hline D & 1809000 & +50 & 75807 & 0.1903 \\
\hline & 1507500 & +25 & 75735 & 0.0952 \\
\hline & 904500 & -25 & 75591 & -0.0952 \\
\hline & 603000 & -50 & 75519 & -0.1903 \\
\hline & & & & 49.6828 \\
\hline & 150750 & +50 & 113254.5 & 24.8287 \\
\hline & 125625 & +25 & 94449.15 & -24.7780 \\
\hline & 75375 & -25 & 56915.25 & -49.4290 \\
\hline & 50250 & -50 & 38263.5 & 49.8097 \\
\hline & & & & 24.9048 \\
\hline & 2.25 & +50 & 113350.5 & -24.9048 \\
\hline & 1.875 & +25 & 94506.75 & -49.8097 \\
\hline & 1.125 & -25 & 56819.25 & \\
\hline & 0.75 & -50 & 37975.5 & 0.1903 \\
\hline & & & & 0.0952 \\
\hline & 36 & +50 & 75807 & -0.0952 \\
\hline & 30 & +25 & 75735 & -0.1903 \\
\hline & 18 & -25 & 75591 & 75519 \\
\hline
\end{tabular}

C. Computation for Item No. 3

The data for Susp.Fempol 6+ the key variables are taken with appropriate units as follows: $\mathrm{D}=962400$ units/year, $\mathrm{Q}=80200$ units/order, $\mathrm{H}=1.7 \mathrm{Rs} / \mathrm{unit}, \mathrm{S}=30 \mathrm{Rs} /$ lot size, daily demand $\mathrm{d}=3849.6$ units, and daily production rate $\mathrm{p}=3860$ units

$$
\begin{gathered}
Q_{P}^{*}=\sqrt{\frac{2 D S}{H\left[1\left(-\frac{d}{P}\right)\right]}} \\
Q_{P}^{*}=\sqrt{\frac{2 * 962400 * 30}{1.7\left[1\left(-\frac{3849.6}{3860}\right)\right]}} \\
Q_{P}^{*}=112280.9 \text { Units } \\
T C=\frac{962400}{80200} 24+\frac{80200}{2} 1.7 \\
T C=R s .68530
\end{gathered}
$$


Table VII. Sensitivity analysis for the key parameters of item no. 3

\begin{tabular}{|c|c|c|c|c|}
\hline Parameter & Changes & Changes (in \%) & Total Cost & Total Cost (in \%) \\
\hline \multirow[t]{4}{*}{$\mathrm{D}$} & 1443600 & +50 & 68710 & 0.2627 \\
\hline & 1203000 & +25 & 68620 & 0.1313 \\
\hline & 721800 & -25 & 68440 & -0.1313 \\
\hline & 481200 & -50 & 68350 & -0.2627 \\
\hline \multirow[t]{4}{*}{$\mathrm{Q}$} & 120300 & +50 & 102495 & 49.5622 \\
\hline & 100250 & +25 & 85500.5 & 24.7636 \\
\hline & 60150 & -25 & 51607.5 & -24.6936 \\
\hline & 40100 & -50 & 34805 & -49.2120 \\
\hline \multirow[t]{4}{*}{$\mathrm{H}$} & 2.55 & +50 & 102615 & 49.7373 \\
\hline & 2.125 & +25 & 85572.5 & 24.8687 \\
\hline & 1.275 & -25 & 51487.5 & -24.8687 \\
\hline & 0.85 & -50 & 34445 & -49.7373 \\
\hline \multirow[t]{4}{*}{$\mathrm{S}$} & 45 & +50 & 68710 & 0.2627 \\
\hline & 37.5 & +25 & 68620 & 0.1313 \\
\hline & 22.5 & -25 & 68440 & -0.1313 \\
\hline & 15 & -50 & 68350 & -0.2627 \\
\hline
\end{tabular}

D. Computation for Item No. 4

The data for Transol 5\% the key variables are taken with appropriate units as follows: $\mathrm{D}=843360$ units/year, $\mathrm{Q}=$ 70280 units/order, $\mathrm{H}=1.9$ Rs. /unit, $\mathrm{S}=35 /$ lot size, daily demand $\mathrm{d}=3373.44$ units, and daily production rate $\mathrm{p}$ $=3400$ units

$$
\begin{gathered}
Q_{P}^{*}=\sqrt{\frac{2 D S}{H\left[1\left(-\frac{d}{P}\right)\right]}} \\
Q_{P}^{*}=\sqrt{\frac{2 * 843360 * 35}{1.9\left[1\left(-\frac{3373.44}{3400}\right)\right]}} \\
Q_{P}^{*}=63067.3 \text { Units } \\
T C=\frac{843360}{70280} 35+\frac{70280}{2} 1.9 \\
T C=R s .67186
\end{gathered}
$$


Table VIII. Sensitivity analysis for the key parameters of item no. 4

\begin{tabular}{|c|c|c|c|c|}
\hline Parameter & Changes & Changes (in \%) & Total Cost & Total Cost (in \%) \\
\hline $\mathrm{D}$ & 1265040 & +50 & 67396 & 0.3126 \\
\hline & 1054200 & +25 & 67291 & 0.1563 \\
\hline & 316260 & -25 & 67081 & -0.1563 \\
\hline & 421680 & -50 & 66976 & -0.3126 \\
\hline $\mathrm{Q}$ & & & & \\
\hline & 105420 & +50 & 100429 & $49 . .4791$ \\
\hline & 87850 & +25 & 83793.5 & 24.7187 \\
\hline & 17570 & -25 & 50634.5 & -24.6353 \\
\hline & 35140 & -50 & 34223 & -49.0623 \\
\hline $\mathrm{H}$ & & & & 49.6874 \\
\hline & 2.85 & +50 & 100569 & 24.8437 \\
\hline & 2.375 & +25 & 83877.5 & -24.8437 \\
\hline & 0.475 & -25 & 50494.5 & -49.6874 \\
\hline & 0.45125 & -50 & 33803 & 0.3126 \\
\hline $\mathrm{S}$ & & & & 0.1563 \\
\hline & 52.5 & +50 & 67396 & -0.1563 \\
\hline & 43.75 & +25 & 67291 & -0.3126 \\
\hline & 8.75 & -25 & 67081 & \\
\hline & 17.5 & -50 & 66976 & \\
\hline & & & & \\
\hline & & & & \\
\hline
\end{tabular}

E. Computation for Item No. 5

The data for Ciprosol Inf the key variables are taken with appropriate units as follows: D = 424200 units/year, Q $=35350$ units/order, $\mathrm{H}=2.9 \mathrm{Rs}$. /unit, $\mathrm{S}=48 /$ lot size and, daily demand $\mathrm{d}=1696.8$ units, and daily production rate $\mathrm{p}=1730$ units

$$
\begin{gathered}
Q_{P}^{*}=\sqrt{\frac{2 D S}{H\left[1\left(-\frac{d}{P}\right)\right]}} \\
Q_{P}^{*}=\sqrt{\frac{2 * 424200 * 48}{2.9\left[1\left(-\frac{1696.8}{1730}\right)\right]}} \\
Q_{P}^{*}=27050.5 \text { Units } \\
T C=\frac{424200}{35350} 48+\frac{35350}{2} 2.9 \\
T C=R s .51833 .5
\end{gathered}
$$


Table IX. Sensitivity analysis for the key parameters of item no. 5

\begin{tabular}{|c|c|c|c|c|}
\hline Parameter & Changes & Changes (in \%) & Total Cost & Total Cost (in \%) \\
\hline \multirow[t]{4}{*}{$\mathrm{D}$} & 636300 & +50 & 52121.5 & 0.5556 \\
\hline & 530250 & +25 & 51977.5 & 0.2778 \\
\hline & 318150 & -25 & 51689.5 & -0.2778 \\
\hline & 159075 & -50 & 51545.5 & -0.5556 \\
\hline \multirow[t]{4}{*}{ Q } & 80025 & +50 & 77270.25 & 49.0740 \\
\hline & 66687.5 & +25 & 64532.68 & 24.4999 \\
\hline & 13337.5 & -25 & 39211.125 & -24.3518 \\
\hline & 26675 & -50 & 26780.75 & -48.3331 \\
\hline \multirow[t]{4}{*}{$\mathrm{H}$} & 4.35 & +50 & 77462.25 & 49.4444 \\
\hline & 3.625 & +25 & 64647.875 & 24.7222 \\
\hline & 2.175 & -25 & 39019.125 & -24.7222 \\
\hline & 1.45 & -50 & 26204.75 & -49.4444 \\
\hline \multirow[t]{4}{*}{$\mathrm{S}$} & 72 & +50 & 52121.5 & 0.5556 \\
\hline & 60 & +25 & 51977.5 & 0.2778 \\
\hline & 36 & -25 & 51689.5 & -0.2778 \\
\hline & 24 & -50 & 51545.5 & -0.5556 \\
\hline
\end{tabular}

F. Computation for Item No. 6

The data for Transol N/S the key variables are taken with appropriate units as follows: D = 676200units/year, Q $=56350$ units/order, $\mathrm{H}=1.8 \mathrm{Rs}$. /unit, $\mathrm{S}=27 \mathrm{Rs}$. /lot size, daily demand $\mathrm{d}=2704.8$ units, and daily production rate $\mathrm{p}=2738$ units

$$
\begin{gathered}
Q_{P}^{*}=\sqrt{\frac{2 D S}{H\left[1\left(-\frac{d}{P}\right)\right]}} \\
Q_{P}^{*}=\sqrt{\frac{2 * 676200 * 27}{1.8\left[1\left(-\frac{2704.8}{2738}\right)\right]}} \\
Q_{P}^{*}=40902.1 \text { Units } \\
T C=\frac{676200}{56350} 27+\frac{56350}{2} 1.8 \\
T C=R s .51039
\end{gathered}
$$


Table X. Sensitivity analysis for the key parameters of item no. 6

\begin{tabular}{|c|c|c|c|c|}
\hline Parameter & Changes & Changes (in \%) & Total Cost & Total Cost (in \%) \\
\hline \multirow[t]{4}{*}{$\mathrm{D}$} & 1014300 & +50 & 51201 & 0.3174 \\
\hline & 845250 & +25 & 51120 & 0.1587 \\
\hline & 508150 & -25 & 50958 & -0.1587 \\
\hline & 338100 & -50 & 50877 & -0.3174 \\
\hline \multirow[t]{4}{*}{$\mathrm{Q}$} & 84525 & +50 & 76288.5 & 49.4710 \\
\hline & 70437.5 & +25 & 63652.95 & 24.7143 \\
\hline & 42262.5 & -25 & 38468.25 & -24.6297 \\
\hline & 28175 & -50 & 26005.5 & -49.0478 \\
\hline \multirow[t]{4}{*}{$\mathrm{H}$} & 2.7 & +50 & 76396.5 & 49.6826 \\
\hline & 2.25 & +25 & 63717.75 & 24.8413 \\
\hline & 1.35 & -25 & 38360.25 & -24.8413 \\
\hline & 0.9 & -50 & 25681.5 & -49.6826 \\
\hline \multirow[t]{4}{*}{$\mathrm{S}$} & 40.5 & +50 & 51201 & 0.3174 \\
\hline & 33.75 & +25 & 51120 & 0.1587 \\
\hline & 20.25 & -25 & 50958 & -0.1587 \\
\hline & 13.5 & -50 & 50877 & -0.3174 \\
\hline
\end{tabular}

\section{RESULTS AND DISCUSSION}

APL produces a total of 32 items. By using ABC analysis technique on the inventory items, they were classified in three classes A, B and C. Six items belongs to A class and 9 to class B and 17 to C. Class A items were taken for further analysis because both of them contributes to $80 \%$ cost monthly inventory cost. For these class A items the optimum production quantity $Q_{P}^{*}$ was determined by using POQ model. After that the total cost was determined for each item. For example, the $Q_{P}^{*}$ for item 1 which have registration number 62324 is as follow:

$\mathrm{D}=$ Average Total Monthly Demand $=80160 * 12=961920$

$\mathrm{d}=$ Daily demand rate $=3847.68$

$\mathrm{p}=$ daily production rate $=3855$

$\mathrm{H}=$ Holding $\operatorname{Cos} \mathrm{t}=$ Rs. 2

$\mathrm{S}=$ Setup Cost $=$ Rs. 40

Thus,

Now the total Cost for this item

$$
\begin{gathered}
Q_{P}^{*}=\sqrt{\frac{2 * 961920 * 40}{2\left[1\left(-\frac{3847.68}{3855}\right)\right]}} \\
Q_{P}^{*}=142349.6
\end{gathered}
$$

$$
\begin{aligned}
& \text { Total Cost } T C=\frac{D}{Q} S+\frac{Q}{2} H \\
& T C=\frac{961920}{80160} 40+\frac{80160}{2} 2 \\
& T C=R s .80640
\end{aligned}
$$

Similarly, it is done for the rest of fourteen items. After these calculations the sensitivity Analysis is performed so that we know the critical factor or variable with is more responsible for the increase or decrease of cost for the particular item. Sensitivity Analysis is performed by changing one variable and keeping all other variables fixed in the Cost equation. 


\section{CONCLUSION}

The proposed research develops the economic production quantity (EPQ) model for different items in Atlantic Pharmaceuticals Laboratories. The managers of Atlantic Pharmaceuticals Laboratories as well as of other industries of similar sectors will be benefited by the outcomes of the results as the optimal solution has been modelled in the most realistic manners. It is concluded from sensitivity analysis that holding cost $(\mathrm{H})$ and quantity per order (Q) are the critical/sensitive parameters as compared to demand rate (D) and setup cost (S). The Effect of variable demand and setup cost are somehow same. Thus, by keeping holding cost and quantity per order in the right level the inventory can be controlled and reduced for each item cost up to $50 \%$ of the cost which is available in present time.

Furthermore, to check the influence of all parameter on the total cost, all parameters are manipulated separately. First of all demand is manipulated in a percentage so for $50 \%$ increase in demand the total cost is increased by $29.7 \%$, and for $25 \%$ increase its influence is $14.8 \%$. Similarly, for $50 \%$ decrease in demand has increased the total cost by $-29.7 \%$ and for $25 \%$ decrease the total cost is decreased by $-14.8 \%$. Secondly, order quantity is manipulated in a percentage so for $50 \%$ increase in order quantity the total cost is increased by $49.5 \%$, and for $25 \%$ increase its influence is $24.7 \%$. Similarly, for $50 \%$ decrease in order quantity has increased the total cost by $-49.1 \%$ and for $25 \%$ decrease the total cost is decreased by $-24.6 \%$.

Now, setup cost is manipulated in a percentage so for $50 \%$ increase in setup cost the total cost is increased by $29.7 \%$, and for $25 \%$ increase its influence is $14.8 \%$. Similarly, for $50 \%$ decrease in setup cost has increased the total cost by $-29.7 \%$ and for $25 \%$ decrease the total cost is decreased by $-14.8 \%$. Further, holding cost is manipulated in a percentage so for $50 \%$ increase in holding cost the total cost is increased by $49.7 \%$, and for $25 \%$ increase its influence is $24.8 \%$. Similarly, for $50 \%$ decrease in holding cost has increased the total cost by $-49.7 \%$ and for $25 \%$ decrease the total cost is decreased by $24.8 \%$.

\section{REFERENCES}

[1] Samak-Kulkarni, S. M., \& Rajhans, N. R. (2013). Determination of optimum inventory model for minimizing total inventory cost. Procedia Engineering, 51, 803-809.

[2] Gupta, L. C. R., \& Gupta, C. K. (2007). ABC and VED Analysis in Medical Stores Inventory Control. MJAFI, 63(4).

[3] Koumanakos, D. P. (2008). The effect of inventory management on firm performance. International journal of productivity and performance management, 57(5), 355-369.

[4] Mahatme, M. S., Hiware, S. K., Shinde, A. T., Salve, A. M., \& Dakhale, G. N. (2012). Medical store management: An integrated economic analysis of a Tertiary Care Hospital in Central India. Journal of Young Pharmacists, 4(2), 114-118.

[5] Arthur, S., \& Crow, H. (2007, September). Prioritising sewerage maintenance using serviceability criteria. In Proceedings of the Institution of Civil Engineers-Water Management (Vol. 160, No. 3, pp. 189-194). Thomas Telford Ltd.

[6] Ahmad, S., \& Prashar, D. (2010). Evaluating municipal water conservation policies using a dynamic simulation model. Water Resources Management, 24(13), 3371-3395.

[7] Sana, S.S. and K. Chaudhuri, An EMQ model in an imperfect production process. International Journal of Systems Science, 2010. 41(6): p. 635-646.

[8] Cárdenas-Barrón, L.E., B. Sarkar, and G. Treviño-Garza, An improved solution to the replenishment policy for the EMQ model with rework and multiple shipments. Applied Mathematical Modelling, 2013. 37(7): p. 5549-5554.

[9] Chung, K.-J., The economic production quantity with rework process in supply chain management. Computers \& Mathematics with Applications, 2011. 62(6): p. 2547-2550.

[10] Sarkar, B., An inventory model with reliability in an imperfect production process. Applied Mathematics and Computation, 2012. 218(9): p. 4881-4891.

[11] Cárdenas-Barrón, L.E., B. Sarkar, and G. Treviño-Garza, An improved solution to the replenishment policy for the EMQ model with rework and multiple shipments. Applied Mathematical Modelling, 2013. 37(7): p. 5549-5554.

[12] Sarkar, B., S.S. Sana, and K. Chaudhuri, An imperfect production process for time varying demand with inflation and time value of money-An EMQ model. Expert Systems with Applications, 2011. 38(11): p. 13543-13548.

[13] Widyadana, G.A. and H.M. Wee, An economic production quantity model for deteriorating items with multiple production setups and rework. International Journal of Production Economics, 2012. 138(1): p. 62-67.

[14] Chang, H.-J., et al., An economic manufacturing quantity model for a two-stage assembly system with imperfect processes and variable production rate. Computers \& Industrial Engineering, 2012. 63(1): p. 285-293.

[15] Cárdenas-Barrón, L.E., B. Sarkar, and G. Treviño-Garza, An improved solution to the replenishment policy for the EMQ model with rework and multiple shipments. Applied Mathematical Modelling, 2013. 37(7): p. 5549-5554.

[16] Cárdenas-Barrón, L.E., A.A. Taleizadeh, and G. Treviño-Garza, An improved solution to replenishment lot size problem with discontinuous issuing policy and rework, and the multi-delivery policy into economic production lot size problem with partial rework. Expert Systems with Applications, 2012. 39(18): p. 13540-13546.

[17] Mahatme, M. S., Hiware, S. K., Shinde, A. T., Salve, A. M., \& Dakhale, G. N. (2012). Medical store management: An integrated economic analysis of a Tertiary Care Hospital in Central India. Journal of Young Pharmacists, 4(2), 114-118.

[18] Kesik, T. J. (2015). Best practices guide: Management of inflow and infiltration in new urban developments. Toronto, ON, Canada: Institute for Catastrophic Loss Reduction.

[19] Rehan, R., Knight, M. A., Unger, A. J., \& Haas, C. T. (2014). Financially sustainable management strategies for urban wastewater collection infrastructure-development of a system dynamics model. Tunnelling and Underground Space Technology, 39, 116-129.

[20] Axelrod, R. (1997). The complexity of cooperation: Agent-based models of competition and collaboration (Vol. 3). Princeton University Press. 